\title{
Comércio internacional de terras e seus reflexos na segurança alimentar dos países africanos
}

\author{
Miguelangelo Gianezini" \\ Clandio Favarini Ruviaro** \\ Fernanda Scharnberg Brandão**** \\ Alex Leonardi $i^{* * * * * *}$
}

\begin{abstract}
Resumo
O comércio internacional contempla atualmente um novo segmento, o de terras estrangeiras, no qual países que possuem deficiências em terrenos aráveis têm especulado e comprado grandes espaços em outros países, o que pode comprometer a sustentabilidade alimentar desses últimos. A questão norteadora deste estudo e seu objetivo residem em apontar alguns reflexos para a segurança alimentar advindos do comércio internacional de terras em países africanos entre os anos de 2000 e 2010. Metodologicamente - sob a ótica das teorias do comércio internacional e dos stakeholders - foram realizados: revisão dos conceitos de comércio internacional de terras; definição de segurança alimentar e caracterização da área de abrangência no continente africano; e levantamento de dados documentais e estatísticos que aliam e/ou confrontam esses elementos na década passada. Constatou-se que os investimentos estrangeiros podem promover incontestáveis mudanças no panorama da produção agropecuária em alguns países africanos, onde a estagnação agrícola e a insegurança alimentar das últimas décadas podem ser revertidos, com melhoria da infraestrutura, aumento da produtividade e possibilidade de geração de emprego e fornecimento de parcela dos alimentos para a população local; ou agravados, com especulação imobiliária e exclusividade de fornecimento da produção aos países estrangeiros.
\end{abstract}

Palavras-chave: Aquisição de terras. Investimentos. Deslocalização agrícola. Abastecimento agrícola.

Doutor em Agronegócios; Universidade do Extremo Sul Catarinense (UNESC); miguelgianezini@ hotmail.com.br

** Doutor em Agronegócios; Universidade Federal da Grande Dourados (UFGD); clandio.ruviaro@ hotmail.com

**** Doutora em Agronegócios; Universidade Federal do Rio Grande do Sul; ferbran@terra.com.br

*** Doutor em Agronegócios; Departamento Intersindical de Estatística e Estudos Socioeconômicos (DIEESE); alleo123@hotmail.com

http://dx.doi.org/10.5335/rtee.v0i41.3732

Submissão: 08/03/2013. Aceite: 05/07/2013 


\section{Introdução}

Com o advento da globalização, a prática secular dos acordos internacionais de comércio modernizou-se, remodelando a economia internacional e influenciando significativamente a condição de muitos países onde o comércio internacional está ligado à comercialização de bens produzidos dentro de suas próprias fronteiras.

$\mathrm{O}$ comércio internacional também contempla atualmente um segmento relativamente novo, o de terras estrangeiras, no qual países com alto consumo de alimentos e que possuem deficiências em terrenos aráveis têm especulado e comprado grandes espaços em outros países (países terceiros), o que pode comprometer a sustentabilidade da autossuficiência alimentar desses últimos.

Esse movimento - também conhecido como offshore farming, deslocalização agrícola ou terceirização de terras (além-mar) - acentuou-se nos últimos anos com a crise dos alimentos (na qual os preços dos grãos aumentaram significativamente no mercado internacional) e vem ganhando espaço na mídia especializada e nos relatórios e documentos de órgãos e institutos de pesquisa que buscam acompanhar o fenômeno.

Nesse contexto, propomos um estudo focado na articulação da condição agropecuária de alguns países da África com o comércio internacional de terras e a questão da segurança alimentar, observando os dados e perspectivas dessa nova conjuntura, com o intuito de identificar os possíveis reflexos para a segurança alimentar advindos do comércio internacional de terras em países africanos.

\section{Método}

Observando o critério de classificação, quanto aos objetivos e procedimentos, optou-se por um estudo exploratório pelo conhecimento do assunto. Quanto aos procedimentos, foram realizados: estudo das teorias do comércio exterior e dos stakeholders; revisão dos conceitos de comércio internacional de terras, definição de segurança alimentar; caracterização da área de abrangência no continente africano; e levantamento de dados documentais e estatísticos que aliam e/ou confrontam esses elementos entre os anos de 2000 e 2010.

Essas leituras, realizadas com o auxílio de ferramentas de pesquisa on-line, aliadas aos dados secundários obtidos junto a institutos e organizações internacionais (FAO, IFPRI, IFAD, WHO, UNCTAD), foi analisada à luz das teorias do comércio internacional (em especial a das vantagens competitivas) e dos stakeholders, com o objetivo de apontar alguns reflexos para a segurança alimentar advindos do comércio internacional de terras em países africanos. 


\section{Resultados}

\subsection{Teorias do comércio exterior}

No âmbito das teorias tradicionais de comércio internacional, a dotação de fatores de produção, trabalho, capital e recursos naturais, podem ser determinantes das trocas entre os países. Em complemento, outros elementos, como economias de escala e de escopo, além de fatores do lado da demanda, como a diferenciação de produto, a tecnologia e o domínio de mercado, devido à competição imperfeita e á política governamental, foram sendo considerados.

Contudo, o poder das explicações tradicionais baseado na dotação de fatores está cada vez menor devido à mobilidade de dotações, como máquinas e equipamentos, pesquisa e desenvolvimento e capital humano com serviços de administração, marketing, engenharia, finanças e outros, que, como reflexos de uma economia globalizada, conferem maior complexidade às questões estudadas.

As modernas teorias do comércio internacional - Resources and trade (Eli Heckscher e Bertil Ohlin); Specific factors and income distribution (Paul Samuelson e Ronald Jones); The standard model of trade (Paul Krugman e Maurice Obsfeld); e The competitive advantage (Michael Porter) - procuram dar conta desses fatores, desenvolvendo explicações dos padrões de comércio e da competitividade a partir do exame das interações estratégicas das empresas e dos governos (COUTINHO et al., 2005).

Nesses modelos, o comércio e os investimentos internacionais ocorrem em mercados imperfeitamente competitivos - nos quais fatores como barreiras à entrada, diferenciação de produtos, economias de escala e progresso tecnológico têm papel importante, em especial no último (PORTER, 1989), no qual o comércio internacional permite a uma nação aumentar sua produtividade, eliminando a necessidade de produzir todos os bens e serviços dentro do próprio país.

\subsection{Teoria dos stakeholders}

A teoria dos stakeholders, relativamente nova no meio científico, auxilia na compreensão de dinâmicas relacionadas ao papel da sociedade e os seus interesses como um todo. A definição de stakeholder (SH) pode ser entendida como qualquer grupo ou indivíduo que possa afetar ou ser afetado, quando da realização de um determinado objetivo, numa organização (FREEMAN, 1984). 
Um stakeholder pode ser também qualquer indivíduo ou grupo que mantém um determinado interesse nas ações, as quais possuem repercussão numa determinada organização (FASSIN, 2008). A partir daí, torna-se fundamental entender a capacidade de legitimação, em relação ao papel exercido por estes, nas diferentes formas de pressões e interesses despertados por suas ações. Normalmente, quanto maior a legitimidade de um stakeholder frente às organizações e aos outros públicos de interesse, maior é sua capacidade de pressão sobre elas (FASSIN, 2008).

\subsection{Segurança alimentar na África Subsaariana}

De maneira específica, a condição de segurança alimentar é considerada existente "quando todos, em qualquer tempo, têm acesso à comida para manter uma vida saudável e ativa de forma suficiente, segura e nutritiva" (World Food Summit, WHO, 1996). Para tal, a Organização Mundial da Saúde ainda considera que essa condição precisa ser construída sobre três pilares: disponibilidade de alimentos; acesso aos alimentos; e uso dos alimentos.

Já, de maneira geral, a segurança alimentar é uma complexa questão de desenvolvimento sustentável ligada à saúde (pelo viés da desnutrição), mas também ligada ao desenvolvimento sustentável econômico, ambiental e comercial.

Quando essa condição é aplicada à África Subsaariana - na qual quase todos os países têm sua história marcada por governos autoritários, cuja intenção primordial não se remete à melhoria das condições socioeconômicas de seus cidadãos -, revela-se uma situação muito desfavorável, agravada por vários motivos nos últimos anos, antes mesmo do início dos investimentos estrangeiros em aquisição de terras: 


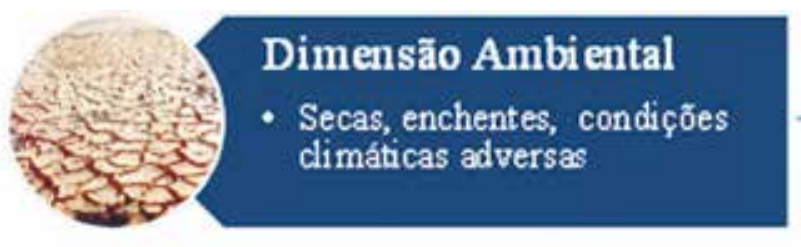

\section{Dimensão Ambiental}

- Secas, enchentes, condições

Lesoto, Somália,

Suazil ândia, Mauritânia,

Gana, Quênia

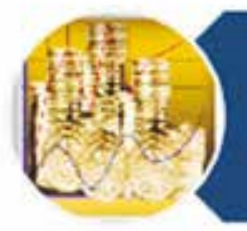

\section{Dimensão Econômica}

- Crise econômica colheitas escassas, insegurança alimentar

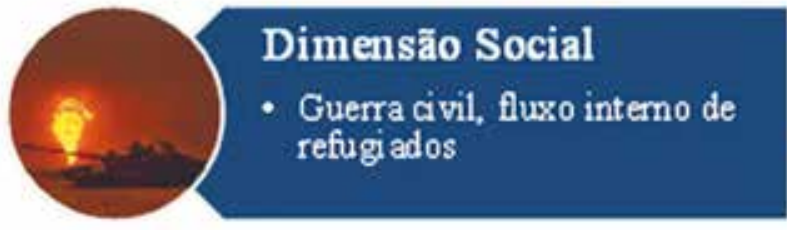

Eritréia, Guiné, Libéria, Serra Leoa, Burundi, República Centro africana, Chade, Sudão, Uganda, República Democrática do Congo, Costa do Marfim

Fonte: Elaborado pelos autores.

Figura 1. Esquema representativo dos atuais pontos críticos na África Subsaariana

Nesse ambiente, encontram-se, portanto, os países que representam os pontos críticos - onde mais de $35 \%$ da população está desnutrida - do chamado "mapa da fome” (Figura 2), totalizando 265 milhões de pessoas nessa condição (FAO, 2009). 


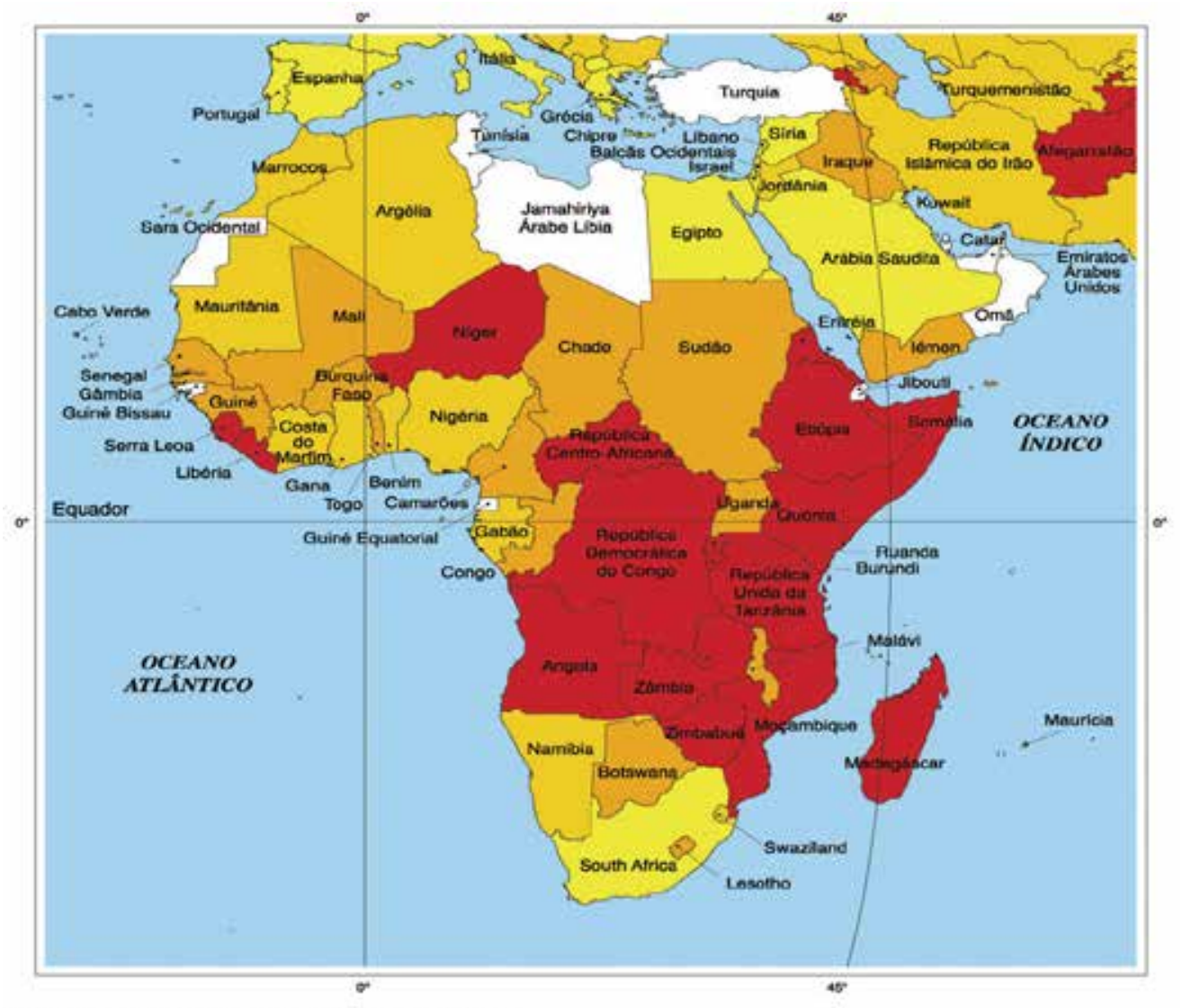

Proporeşo na populaço total (pereentagem)

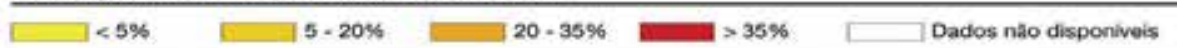

Fonte: FAONGIS (ESNP / SOPNQ, 2003

Fonte: http://www.fao.org/economic/ess/food-security-statistics/fao-hunger-map/en

Figura 2. Mapa da fome no continente africano: proporção de pessoas subnutridas.

Do ponto de vista da produtividade agrícola, a África esteve estagnada nas três últimas décadas (IFPRI, 2006). Isso criou sérios problemas de insegurança alimentar e tem apresentado um grande desafio para o desenvolvimento dos países, uma vez que o setor agrícola constitui a base de muitas economias (UNCTAD, 2010), sendo a maior fonte de emprego e subsistência para a maioria da população. Contudo, nos últimos anos - com a aquisição de terras em larga escala por grupos e países estrangeiros -, esse quadro defronta-se com uma possibilidade de reversão ou agravamento.

Isso porque verifica-se uma tendência democratizadora na região, com eleições multipartidárias realizadas regularmente. Essa nova situação de relativa segurança 
institucional (política e jurídica) tem encorajado não somente multinacionais do setor agroalimentar, mas também outros governos a buscar em negociação com países africanos no âmbito desse novo negócio internacional, o comércio de terras.

\subsection{Comércio internacional de terras}

As atuais aquisições de terra em larga escala e investimentos agrícolas têm se destacado no contexto da expansão das relações econômicas entre a África e o resto do mundo. Desde o início do século XXI, a liberalização econômica, a globalização dos transportes e das comunicações, e a demanda mundial por alimentos, energia e commodities, estimularam os investimentos estrangeiros em muitas partes da África - especialmente em indústrias extrativas e na agricultura para alimentos e combustível (VON BRAUM; MEINZEN-DICK, 2009).

Os relatórios internacionais e a mídia especializada apontam que a região da África Subsaariana é um hotspot para aquisição internacional de terras, com destaque para países como Sudão, Etiópia e Moçambique. Contudo, as mesmas fontes indicam que alguns dos acordos foram suspensos.

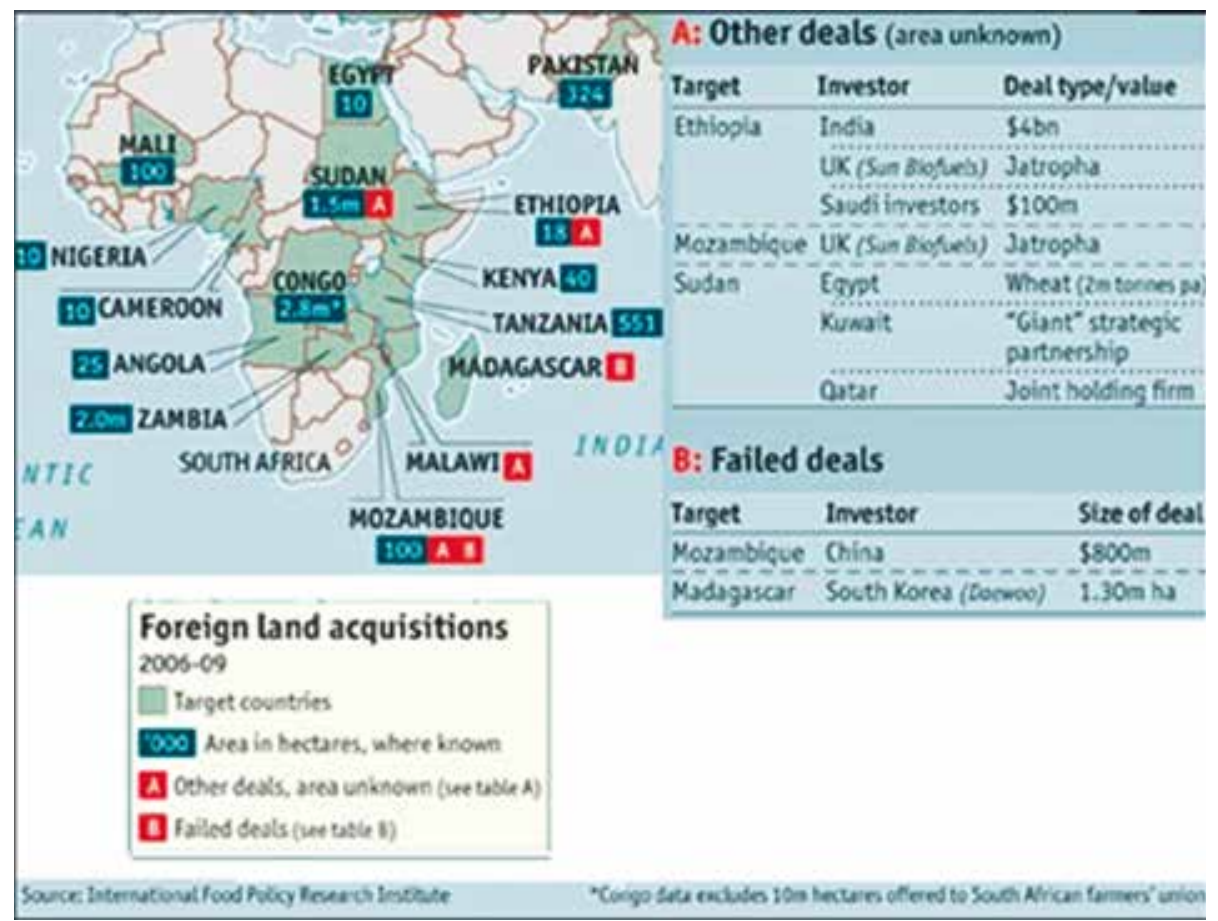

Fonte: Adaptado de IFPRI; The economist; Prospectivevalue, 2009

Figura 3. Mapa da aquisição de terras estrangeiras: países-alvos e tipos de acordo 
Em 2007, os investimentos estrangeiros diretos na África Subsaariana ultrapassaram os US $\$ 40$ bilhões, superando os US $\$ 28$ bilhões de 2006 e os US $\$ 21$ bilhões de 2005 (UNCTAD, 2008). Embora boa parte desses investimentos esteja concentrada em países com petróleo e recursos minerais (Nigéria), outros países, como Etiópia, Gana, Moçambique, Sudão, Tanzânia e Zâmbia, que não despertavam quase nenhum interesse até o início dos anos 1990, experimentam um considerável acréscimo de investimento estrangeiro (Gráfico 2).

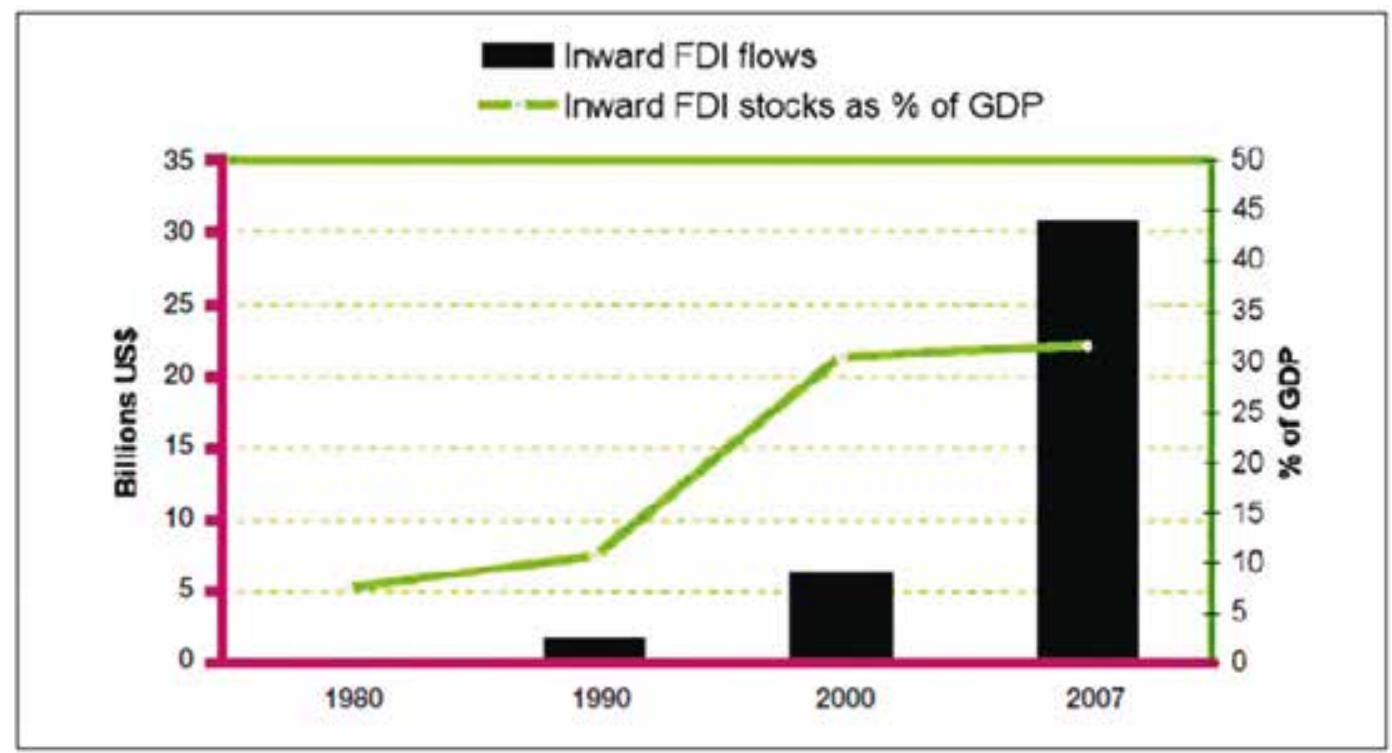

Fonte: UNCTAD, 2008.

Gráfico 1. Fluxo interno de investimentos estrangeiros diretos na África Subsaariana.

A percepção de disponibilidade de terras na África atraiu a atenção de governos interessados em assegurar o suprimento de alimento e de combustível, além de atrair investidores ávidos para aproveitar a demanda global por comida e energia. 


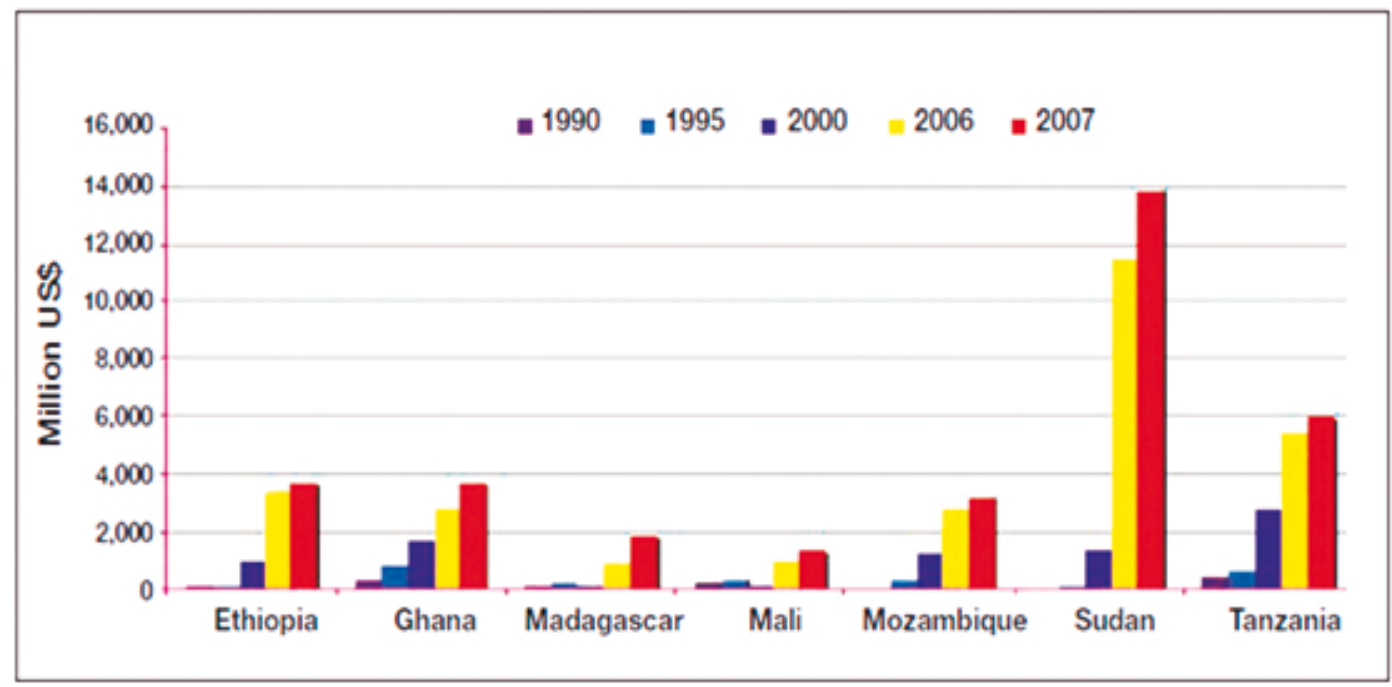

Fonte: UNCTAD, 2008.

Gráfico 2. Investimentos estrangeiros em alguns países da África Subsaariana.

Contudo, nem todos estes investimentos estrangeiros na região são em terras e, dentro desses, nem todas as aquisições são destinadas à produção agrícola, havendo aquisições para fins de extrativismo, indústria, infraestrutura e outros.

Os dados específicos para agricultura ainda são poucos e/ou incompletos, e os relatórios apontam essa dificuldade (IFPRI, 2006; UNCATD, 2008; 2010).

Outro elemento importante para a compreensão dos reflexos do comércio internacional de terras na segurança alimentar desses países diz respeito às questões legais.

Apesar de serem de simples compreensão - o comércio de terras envolve duas partes, uma compradora, (empresas ou governos estrangeiros) e uma vendedora (governo de um país africano ou, muito raramente, um vendedor privado africano) - as leis e acordos que regulamentam essas atividades são frágeis e observa-se que, em especial, os arrendamentos de terra por longos períodos podem comprometer a estabilidade socioeconômica de alguns países. 


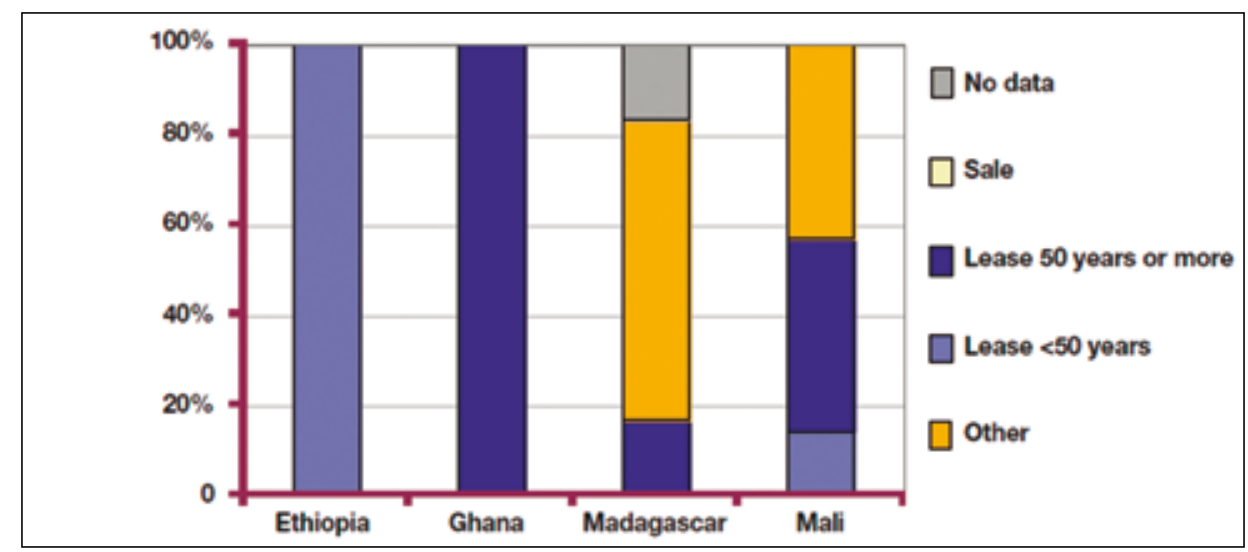

Fonte: FAO, IIED, IFAD, 2009.

Gráfico 3. Tipos de direitos de posse transferidos.

Essa é uma preocupação relacionada aos contratos, pois, se após o acerto legal, forem observados acordos agrícolas como o da Organização Mundial do Comércio (AAG/OMC), estão previstas sanções não comerciais que irão orientar as negociações, sinalizando para a necessidade de cumprimento dos compromissos assumidos de maneira equitativa entre todos os membros. Nesse contexto, temas como o abastecimento e a segurança alimentar e a proteção do meio ambiente são relevantes para os países que arrendam ou vendem seu território.

Além disso, por se tratar de uma nova modalidade de comércio, documentos, relatórios, organizações não governamentais e a imprensa internacional observam a necessidade de criação de um código de conduta que leve em consideração alguns elementos, a fim de mitigar os riscos de insegurança alimentar para a população desses países africanos: transparência nas negociações; respeito pela existência do direito à terra, incluindo os direitos habituais e comuns à propriedade; distribuição dos benefícios; sustentabilidade ambiental; e aderência às políticas comerciais de cada país.

\section{Discussão}

O comércio internacional de terras não se encontra consolidado e as análises acerca de seus desdobramentos ainda são pouco estudadas.

A leitura dos documentos e relatórios que abordam a questão apontam que esse tipo de comércio deve se tornar uma tendência na medida em que se acentuarem os riscos de insegurança alimentar como reflexo do crescimento da população mundial (que ultrapassará os 8 bilhões de pessoas em 2025), do incremento da concorrência entre utilizações para fins alimentares ou produção de energia (Ex. grãos para biocombustíveis), dos efeitos ambientais, da diminuição dos recursos hídricos e, consequentemente, da diminuição de terras aráveis. 
As teorias do comércio internacional e stakeholders, quando aplicadas à temática pesquisada apontam dois desafios: a dificuldade de compreensão desse novo fenômeno, que, devido à complexidade de sua natureza transnacional, confronta os princípios das teorias tradicionais do comércio internacional, encontrando compreensão apenas a partir de Porter, com a eliminação da necessidade de produzir todos os bens e serviços dentro do próprio país; e a relação entre forças de estabilização/inércia e perspectivas de rupturas tecnológicas/institucionais promovidas pelos players ou stakeholders presentes nesse contexto.

Os stakeholders possuem sua relevância como interface para esse e outros contextos e aparecem nos documentos e relatórios representados pelos investidores, que podem buscar opções para maximizar a segurança para o investimento e ganhos sustentáveis de desenvolvimento; pelos governos dos países africanos, que podem colocar o desenvolvimento sustentável no centro de decisões e definir que tipo de investimentos desejam atrair; pela sociedade civil e seus grupos de apoio, que podem desenvolver opções para maximização dos benefícios líquidos de investimentos da terra, limitando impactos excludentes; e pelas agências de desenvolvimento internacional, que podem catalisar mudanças positivas.

Por fim, observa-se que os estudos realizados a pedido das Nações Unidas para Alimentação e Agricultura (FAO) e o Fundo Internacional de Desenvolvimento Agrícola (IFAD) apontam que as aquisições de grande escala realizadas por países investidores interessados na segurança alimentar podem trazer muitas oportunidades, incluindo a garantia de novos postos de trabalho, o investimento em infraestrutura e o aumento da produtividade agrícola, ainda que ponderações críticas deem conta da possibilidade da um "neocolonialismo", por meio de uma "nova onda de terceirização mundial".

\section{Conclusões}

Com a realização deste estudo, constatou-se que os investimentos estrangeiros podem promover incontestáveis mudanças no panorama da produção agrícola e pecuária em alguns países africanos, como ocorrido na última década.

A estagnação agrícola e a insegurança alimentar provocadas por diversos fatores ao longo das últimas décadas podem ser agravados ou revertidos, dependendo da forma como os acordos internacionais, especialmente entre governos, forem celebrados.

Tais acordos podem ser prejudiciais com a especulação imobiliária e a exclusividade de fornecimento da produção ao país estrangeiro, agravando a situação de dependência e insegurança alimentar nos países da África Subsaariana.

Nesse cenário desfavorável, pode igualmente estar surgindo oportunidades de inserção em um mercado globalizado, com a melhoria da infraestrutura, o aumento da produtividade e a possibilidade de geração de emprego, aliadas ao fornecimento de parcela dos alimentos produzidos para a população local. 


\title{
International land trade and its effects on food security in Africa
}

\author{
Abstract
}

\begin{abstract}
International trade currently contemplates a new segment: the large-scale foreign land acquisition, in which countries that have deficiencies in arable land have speculated, and bought large areas in other countries, which may impact in the food security of these "sellers" countries. The main question of this study and its goal is to point out some consequences for food security arising from foreign investments in large-scale foreign land acquisition in African countries between 2000 and 2010. Methodologically - from the perspective of international trade and stakeholders theories - it was made: Review of concepts of international trade land, definition of food security and characterization of the coverage area on the African continent, and survey data that combine documentary and statistical these elements in the last ten years. It was found that foreign investment can promote incontestable changes in the agriculture field of some African countries, where stagnating agricultural and food insecurity in recent decades can be: reversed, with improved infrastructure, increased productivity and the possibility of employment generation and food supply for local people; or aggravated, with speculation and exclusive supply from production to a foreign country.
\end{abstract}

Keywords: Land acquisition; Investments; Offshore farming; Agricultural supply.

\section{El comercio internacional de tierras y sus efectos sobre la seguridad alimentaria en los países africanos}

\section{Resumen}

El comercio internacional incluye en la actualidad un nuevo segmento (países extranjeros), en el que los países que tienen deficiencias en las tierras de cultivo han especulado y comprado grandes extensiones en otros países, lo que puede comprometer la sostenibilidad alimentaria. La cuestión principal de este estudio y su objetivo reside en señalar algunas consecuencias para la seguridad alimentaria, derivadas del comercio internacional de tierras en los países africanos entre los años de 2000 y 2010. Metodológicamente - bajo la perspectiva de las teorías del comercio internacional y stakeholders - se realizaron: la revisión de los conceptos de comercio internacional de tierras; la definición de la seguridad alimentaria y la caracterización de la zona de estudio en el continente africano; y el levantamiento de documentos y datos estadísticos que combinan/confrontar estos elementos en la última década. Los resultados muestran que la inversión extranjera puede promover cambios innegables en el panorama de la producción agrícola en algunos países africanos, donde la inseguridad agrícola y alimentaria estancada en las últimas décadas puede ser: revertida con la mejora de la infraestructura, el aumento de la productividad y la capacidad de generar empleo y la prestación de parte de los alimentos para la población local; o agravada, con la especulación y la oferta exclusiva de la producción a países extranjeros.

Palabras clave: Adquisición de tierras; Inversiones; Offshore farming; Oferta agrícola. 


\section{Nota}

1 International Food Policy Research Institute (IFPRI), 2009. Disponível em: <http://www.prospectivevalue. com/wordpress/wp-content/uploads/2009/07/picture-1.jpg>. Acesso em: 14 mar. 2011.

\section{Referências}

COTULA, L. et al. Land grab or development opportunity? Agricultural Investment And International Land Deals In Africa, IIED/FAO/IFAD, Londres/Roma, 2009. Disponível em: <http://www. ifad.org/pub/land/land_grab.pdf>. Acesso em: 27 jul. 2012.

COUTINHO et al. De smith a porter: um ensaio sobre as teorias de comércio exterior. $R e$ vista de Gestão USP, São Paulo, v. 12, n. 4, p. 101-113, out./dez., 2005. Disponível em: <http://www.revistasusp.sibi.usp.br/scielo.php?script=sci_pdf\&pid=S1 809-2276200 50004 00008\&lng=pt\&nrm=iso\&tlng =pt>. Acesso em: 03 jun. 2012.

IFPRI. Agricultural R\&D in Sub-Saharan Africa: An Era of Stagnation. IFPRI, Washington DC, United States, 2006. Disponível em: <http://www.ifpri.org/ publication/agricultural-rd-sub-saharan-africa-0?print>. Acesso em: 23 mai. 2012.

FASSIN, Y. The Stakeholder Model Refined. Journal of Business Ethics. v. 84. p. 113-135, 2008. Disponível em: <http://www.springerlink.com/content/m27207u6m7057522 /fulltext.pdf>. Acesso em: 02 jun. 2012.

FOOD AND AGRICULTURE ORGANIZATION OF THE UNITED NATIONS. The state of food insecurity in the world: economic crises - impacts and lessons learned. Rome, 2009. Disponível em: <http://www.fao.org/docrep/013/i1683e/i1683 e.pdf>. Acesso em: 23 mai. 2012.

FREEMAN, R. E. Strategic management: A stakeholder approach. Boston: Pitman, 1984.

PORTER, M. E. A vantagem competitiva das nações. Rio de Janeiro: Campus, 1989.

UZQUIZA, L. Food security and international trade: a Latin American perspective about implications for multilateral and regional institutions. 4th Annual Meeting of the GARNET network Food Security and Sustainable Development: Challenges for the Governance of International Relations. Roma, 11-13 Nov., 2009. Disponível em: <http://www.idra.it/garnetpapers/C10Laura_Uzquiza.pdf>. Acesso em: 26 jul. 2012.

UNITED NATIONS CONFERENCE ON TRADE AND DEVELOPMENT. Technology and innovation report. Enhancing Food Security in Africa Through Science, Technology and Innovation. UNCTAD, 2010. Disponível em: <http://unctad.org/en/ docs/tir2009_en.pdf>. Acesso em: 15 jun. 2012.

UNITED NATIONS CONFERENCE ON TRADE AND DEVELOPMENT. World Investment Report 2008: Transnational Corporations and the Infrastructure Challenge, Geneva, UNCTAD, 2008. Disponível em: <http://unctad.org/en/Docs/ wir2008_en.pdf>. Acesso em: 14 jun. 2012.

VON BRAUM, J. e MEINZEN-DICK R. "Land grabbing” by foreign investors in developing countries: risks and opportunities. IFPRI Policy Brief 13. April, 2009. Disponível em: <http://www. ifpri.org/sites/default/files/publications/bp013all.pdf>. Acesso em: 14 jun. 2012.

WORLD HEALTH ORGANIZATION. World Food Summit. Declaration on World Food Security and World Food. Summit Plan of Action. Rome, 1996. Disponível em: <http://www.fao.org/wsfs/ world-summit/en/>. Acesso em: 12 jun. 2012. 